\title{
Fate of surgical patients with small nonfunctioning pancreatic neuroendocrine tumors: an international study using multi-institutional registries
}

\author{
Category: Original article
}

Running title: Prognosis after resection of small pNETs

In Woong Han, $\mathrm{MD}, \mathrm{PhD}^{1}$ (cardioman76@gmail.com) Jangho Park, $\mathrm{MD}^{2}$ (khumedicaljang@hanmail.net)

Eun Young Park, MS ${ }^{3}$ (13140@ncc.re.kr)

So Jeong Yoon, $\mathrm{MD}^{1}$ (sojeong.yoon@samsung.com)

Gang Jin, MD, $\mathrm{PhD}^{4}$ (jingang@smmu.edu.cn)

Dae Wook Hwang, MD, PhD ${ }^{5}$ (dwhwang@amc.seoul.kr)

Kuirong Jiang, MD, $\mathrm{PhD}^{6}$ (jiangkuirong@163.com)

Wooil Kwon, $\mathrm{MD}, \mathrm{PhD}^{7}$ (willdoc78@gmail.com)

Xuefeng Xu, MD, $\mathrm{PhD}^{8}$ (xu.xuefeng@zs-hospital.sh.cn)

Jin Seok Heo, MD, PhD ${ }^{1}$ (jsheo@skku.edu)

Deling Fu, MD, PhD ${ }^{9}$ (surgeonfu@163.com)

Woo Jung Lee, MD, PhD ${ }^{10}$ (WJLEE@yuhs.ac)

Xueli Bai, MD, PhD ${ }^{11}$ (shirleybai@zju.edu.cn)

Yoo-Seok Yoon, MD, PhD ${ }^{12}$ (yoonys@snubh.org)

Yin-Mo Yang, MD, $\mathrm{PhD}^{13}$ (yangyinmo@263.net)

Keun Soo Ahn, MD, PhD ${ }^{14}$ (ahnksmd@gmail.com)

Chunhui Yuan, MD, PhD ${ }^{15}$ (ychdoctor@163.com)

Hyeon Kook Lee, MD, PhD ${ }^{16}$ (leehk@ewha.ac.kr)

Bei Sun, MD, PhD ${ }^{17}$ (sunbei70@tom.com)

Eun Kyu Park, MD, PhD ${ }^{18}$ (iameunkyu@gmail.com)

Seung Eun Lee, MD, $\mathrm{PhD}^{19}$ (selee508@cau.ac.kr)

Sunghwa Kang, MD, PhD 20 (kang3860@naver.com)

Wenhui Lou, MD, PhD (lou.wenhui@zs-hospital.sh.cn), Co-corresponding author

Sang-Jae Park, MD, PhD² (spark@ncc.re.kr), Co-corresponding author

* Sang-Jae Park and Wenhui Lou contributed equally to this work as co-corresponding authors.

\section{Location of department and institution:}

${ }^{1}$ Department of Surgery, Division of Hepatobiliary and Pancreatic Surgery, Samsung Medical Center, Sungkyunkwan University School of Medicine, 81 Irwon-ro, Gangnam-gu, Seoul 06351, South Korea.

${ }^{2}$ Center for Liver and Pancreatobiliary Cancer, ${ }^{3}$ Biostatistics Collaboration Team, Research Institute and Hospital of National Cancer Center, 323 Ilsan-ro, Ilsandong-gu, Goyang-si Gyeonggi-do, 10408, South Korea.

${ }^{4}$ Department of Hepato-Biliary-Pancreatic Surgery, Changhai Hospital, Second Military Medical University, Shanghai 200433, P.R. China.

${ }^{5}$ Division of Hepatobiliary and Pancreatic Surgery, Department of Surgery, Asan Medical Center, University of Ulsan College of Medicine, Seoul, South Korea

${ }^{6}$ Department of General Surgery, Pancreas Center of The First Affiliated Hospital of Nanjing Medical University, Nanjing 210029, P.R. China.

${ }^{7}$ Department of Surgery and Cancer Research Institute, Seoul National University College of Medicine, Seoul, South Korea

${ }^{8}$ Department of Pancreatic Surgery, Zhongshan Hospital, Fudan University, Shanghai 200032, P.R. China.

${ }^{9}$ Department of Pancreatic Surgery, Huashan Hospital, Fudan University, Shanghai 200040, P.R. China.

${ }^{10}$ Division of Hepatobiliary and Pancreatic Surgery, Department of Surgery, Yonsei University College of Medicine, Pancreatobiliary Cancer Center, Yonsei Cancer Center, Severance Hospital, Seoul, South Korea

${ }^{11}$ Department of Hepatobiliary and Pancreatic Surgery, The Second Affiliated Hospital of Zhejiang University, Hangzhou 310009, P.R. China.

${ }^{12}$ Department of Surgery, Seoul National University Bundang Hospital, Seoul National University College of 
Medicine, South Korea

${ }^{13}$ Department of General Surgery, The First Hospital of Peking University, Beijing 100034, P.R. China.

${ }^{14}$ Department of Surgery, Keimyung University Dongsan Hospital. Keimyung University School of Medicine, South Korea

${ }^{15}$ Department of General Surgery, The Third Hospital of Peking University, Beijing 100083, P.R. China.

${ }^{16}$ Department of Surgery, Ewha Womans University College of Medicine, Seoul, South Korea

${ }^{17}$ Department of Hepatobiliary and Pancreatic Surgery, The First Affiliated Hospital of Harbin Medical University, Harbin 150001, P.R. China

${ }^{18}$ Division of Hepatobiliary and Pancreatic Surgery, Department of General Surgery, Chonnam National University Hospital, South Korea

${ }^{19}$ Department of Surgery, Chung-Ang University Hospital, Chung-Ang University College of Medicine, Seoul, South Korea

${ }^{20}$ Division of Hepatobiliary and Pancreatic surgery, Department of Surgery, Dong-A University hospital, South Korea

\title{
Corresponding author:
}

Sang-Jae Park, M.D., Ph.D.

Center for Liver and Pancreatobiliary Cancer, Research Institute and Hospital of National Cancer Center, 323 Ilsan-ro, Ilsandong-gu, Goyang-si Gyeonggi-do, 10408, South Korea

E-mail: spark@ncc.re.kr

Tel: +82-31-920-1640

Wenhui Lou, M.D., Ph.D.

Department of Pancreatic Surgery, Zhongshan hospital, Fudan University, Shanghai 200032, P.R. China.

E-mail: lou.wenhui@zs-hospital.sh.cn

Tel: +86-13681971683

Disclosures: any potential conflicts are not relevant to the manuscript

\begin{abstract}
Several treatment guidelines for sporadic, nonmetastatic nonfunctioning neuroendocrine tumors of the pancreas (NF-pNETs) have recommended resection, however, tumors $\leq 2 \mathrm{~cm}$ do not necessarily need surgery. This study aimed to establish a surgical treatment plan for NF-pNETs $\leq 2 \mathrm{~cm}$. From 2000 to 2017, 483 patients who underwent resection for NF-pNETs $\leq 2 \mathrm{~cm}$ in 18 institutions from Korea and China were enrolled and their medical records were reviewed. Median age was 56 (range 16-80) years. The 10-year overall survival rate (10Y-OS) and recurrence-free survival rate (10Y-RFS) were 89.8 and $93.1 \%$, respectively. In multivariable analysis, tumor size $(>1.5 \mathrm{~cm} ; p=0.001)$ and nodal metastasis $(p=0.013)$ were independent adverse prognostic factors for OS. Perineural invasion $(p=0.008)$ and high Ki-67 index $(\geq 3 \% ; p<0.001)$ were independent prognostic factors for poor RFS. NF-pNETs $\leq 2 \mathrm{~cm}$ showed unfavorable prognosis after resection when the tumor was larger than $1.5 \mathrm{~cm}$, Ki-67 index $\geq 3 \%$, or nodal metastasis was present. NF-pNET patients with tumors $\leq 1.5 \mathrm{~cm}$ can be observed if the preoperative $\mathrm{Ki}-67$ index is under $3 \%$, and if nodal metastasis is not suspected in preoperative radiologic studies. These findings support the clinical use to make decision about small NF-pNETs.
\end{abstract}

\section{Keywords:}

Nonfunctioning neuroendocrine tumor of pancreas; Prognosis; Resection; Risk factors 


\section{Introduction}

Pancreatic neuroendocrine tumors (pNETs) account for less than $2 \%$ of all pancreatic cancers $[1,2]$ and approximately $10 \%$ of tumors arising from the pancreas.[3] Their rare incidence and indolent biologic behavior with variable malignant potential has made it difficult to establish optimal management for pNETs. [1,3,4] Nonfunctioning neuroendocrine tumors of the pancreas (NF-pNET) account for 50-75\% of all pNETs, and awareness of their incidence and prevalence in recent decades has increased due to the development of imaging technology and improved pathological diagnosis.[1,2,5-7]

Several treatment guidelines for NF-pNETs have recommended resection, however, evidence is lacking for the best way to treat NF-pNETs $\leq 2 \mathrm{~cm}$.[8-12] Some studies suggest that many small, asymptomatic pNETs are biologically indolent, do not enlarge or progress over time, show low nodal metastasis, and thus can be safely observed.[13,14] However, several reports emphasized that even small tumors, can behave aggressively and that survival times improved after resection.[15-17] Currently, it is unclear how to preoperatively predict the malignant potential of small NF-pNETs, how to select patients for surgery, and how to determine the approach and extent of surgery that should be performed in patients selected for resection.

The aims of this Korean- Chinese multi-institutional study were to analyze postoperative outcomes and prognostic factors after resection of sporadic, nonmetastatic NF-pNETs $\leq 2 \mathrm{~cm}$ and to suggest surgical indications.

\section{Results}

\subsection{Clinicopathological characteristics}

Table 1 provides the clinicopathologic details of the 483 patients. The median patient age was 56 (range 16- 80) years with a male to female ratio of 1:1.44 (198:285). The tumors of 197 patients $(40.8 \%)$ were in the pancreas head, and those of 286 patients were in the body or tail. The median tumor size was $1.4 \mathrm{~cm}(0.1-2.0 \mathrm{~cm})$ and 24 patients (5.0 \%) had multiple tumors. Using the WHO 2010 grades $(\mathrm{G}), 364$ patients $(75.8 \%)$ had G1, $105(21.9 \%)$ had G2, and $11(2.3 \%)$ had G3. The numbers of patients with Ki-67 index $<3 \%, 3 \%-20 \%$, and $>20 \%$ were 388 $(82.6 \%), 73(15.5 \%)$, and $9(1.9 \%)$, respectively. The numbers of patients with mitosis counts $<2,2-20$, and $>$ 20 were $401(91.1 \%), 39(8.9 \%)$, and $0(0 \%)$, respectively. Among 243 patients who had lymph node dissection or sampling, 32 patients (13.2\%) had lymph node metastasis (LNM) and these patients accounted for $7.1 \%$ of all 483 patients (Table 1$)$. 
Table 1. Clinical characteristics of the patients.

\begin{tabular}{|c|c|c|c|}
\hline Characteristics & Total $(N=483)$ & Korea $(N=329)$ & China $(N=154)$ \\
\hline Sex (male / female) & $198 / 285(1: 1.44)$ & $134 / 195(1: 1.46)$ & $64 / 90(1: 1.41)$ \\
\hline Age (median, range) & $56.0(16-80)$ & $56.0(17-77)$ & $55.0(16-80)$ \\
\hline Tumor size (median, range) $(\mathrm{cm})$ & $1.4(0.1-2.0)$ & $1.4(0.1-2.0)$ & $1.5(0.1-2.0)$ \\
\hline Tumor size $(\leq 1 / 1.1-1.5 />1.5-2 \mathrm{~cm})(\mathrm{n}, \%)$ & $146(30.2 \%) / 188(38.9 \%) / 149(30.8 \%)$ & $95(28.9 \%) / 131(39.8 \%) / 103(31.3 \%)$ & $51(33.1 \%) / 57(37.0 \%) / 46(29.9 \%)$ \\
\hline Number of tumors $(1 />1)(\mathrm{n}, \%)$ & $459(95.0 \%) / 24(5.0 \%)$ & $316(96.0 \%) / 13(4.0 \%)$ & $143(92.9 \%) / 11(7.1 \%)$ \\
\hline Tumor location (head / elsewhere) (n, \%) & $197(40.8 \%) / 286(59.2 \%)$ & $137(41.6 \%) / 192(58.4 \%)$ & $60(39.0 \%) / 94(61.0 \%)$ \\
\hline WHO 2010 grade $(1 / 2 / 3)(n, \%)$ & $364(75.8 \%) / 105(21.9 \%) / 11(2 \%)$ & $259(78.7 \%) / 66(20.1 \%) / 4(1.2 \%)$ & $105(68.2 \%) / 39(25.3 \%) / 7(4.5 \%)$ \\
\hline Ki-67 index (median, range) $(\%)$ & $1.0(0-80)$ & $1.0(0-80)$ & $2.0(0-60)$ \\
\hline Ki-67 index $(<3 / 3-20 />20)(n, \%)$ & $388(82.6 \%) / 73(15.5 \%) / 9(1.9 \%)$ & $282(85.7 \%) / 34(10.3 \%) / 3(1.0 \%)$ & $106(68.8 \%) / 39(25.3 \%) / 6(3.9 \%)$ \\
\hline Mitotic count (median, range) & $1(0-20)$ & $1(0-20)$ & $1(0-20)$ \\
\hline Mitotic count $(<2 / \geq 2)(\mathrm{n}, \%)$ & $401(91.1 \%) / 39(8.9 \%)$ & $284(90.5 \%) / 30(9.6 \%)$ & $106(70.2 \%) / 45(29.8 \%)$ \\
\hline Nodal dissection (n, \%) & $243(50.3 \%)$ & $164(49.8 \%)$ & $79(51.3)$ \\
\hline Nodal metastasis (n, \%) & $32(7.1 \%)$ & $15(4.6 \%)$ & $17(13.6 \%)$ \\
\hline Tumor margin $(+)(\mathrm{n}, \%)$ & $27(5.7 \%)$ & $24(7.3 \%)$ & $3(2 \%)$ \\
\hline Adjacent organ invasion (n, \%) & $9(1.9 \%)$ & $2(0.6 \%)$ & $7(4.5 \%)$ \\
\hline Vascular invasion (n, \%) & $48(10.3 \%)$ & $38(11.6 \%)$ & $10(7.4 \%)$ \\
\hline Perineural invasion (n, \%) & $44(9.6 \%)$ & $27(8.2 \%)$ & $17(13.1 \%)$ \\
\hline
\end{tabular}




\subsection{Postoperative complications according to type of surgery}

Major complications occurred in 28 patients ( $8.5 \%$ ), and the Postoperative pancreatic fistula (POPF; grade B or C) rate was $7.6 \%(n=25)$ among the Korean patients. The postoperative outcomes of patients according to Parenchymal-sparing resections (PSR) or standard resection among the Korean patients are shown in Table S1. No differences were observed in major complications, delayed gastric emptying, POPF, or postoperative hemorrhage. In addition, no statistically significant differences were found in any complication between patients who underwent MIS and those who underwent open resection among the Korean patients (Table S2).

\subsection{Survival and risk factor analysis}

The overall survival (OS) rate at 5 years and 10 years was 95.7 and $89.8 \%$, respectively (Figure 1a). The OS in patients with tumors $\leq 1.5 \mathrm{~cm}$ was more favorable than that in patients with tumors $>1.5 \mathrm{~cm}(p<0.001$, Figure $1 b)$. However, the OS in patients with tumors $\leq 1.0 \mathrm{~cm}$ did not differ from those with tumors $1.0-1.5 \mathrm{~cm}(p=0.511$, Figure 1c). In multivariable analysis, older age ( $>65$ years; HR 4.26, $95 \%$ CI 1.84-9.84, $p=0.001)$, tumor size $(>1.5 \mathrm{~cm}$; HR 4.28, $95 \%$ CI 1.80-10.18, $p=0.001)$, and LNM (HR 3.32, $95 \%$ CI 1.29-8.50, $p=0.013)$ were significant prognostic factors for OS. These results are summarized in Table 2.

The recurrence-free survival (RFS) rate at 5 years and 10 years was 95.7 and $93.1 \%$, respectively (Figure 2a). Total recurrence was identified in 21 patients $(4.3 \%)$. The most common site of recurrence was the liver $(n=11)$, followed by the lymph nodes $(n=6)$. There were 7 local recurrences and 11 recurrences in multiple sites. RFS in patients with tumors $\leq 1.5 \mathrm{~cm}$ was more favorable than that in patients whose tumors were $>1.5 \mathrm{~cm}(p=0.022$, Figure 2b). In particular, the RFS in patients with LNM was poorer than in those without LNM $(p<0.001$, Figure $2 \mathrm{~d}$ ). In the multivariable analysis, high Ki-67 index ( $\geq 3 \%$; HR 9.06, 95\% CI 3.01-27.30, $p<0.001)$, nodal metastasis (HR 3.68, $95 \%$ CI 1.22- 11.11, $p=0.021$ ), and perineural invasion (HR 4.36, $95 \%$ CI 1.48- 12.87, $p=$ 0.008 ) were independent prognostic factors for RFS. Table 3 summarizes these results. Additionally, the distribution of risk factors for OS and RFS is described in Table S3.

Further analysis was conducted on Korean patients for type of surgery and the OS of PSR showed no significant difference in prognosis compared to standard surgery, whereas MIS showed favorable prognosis compared to open resection (data not shown). In addition, RFS did not differ significantly between PSR and standard resection, or between MIS and open resection in Korean patients (data not shown).
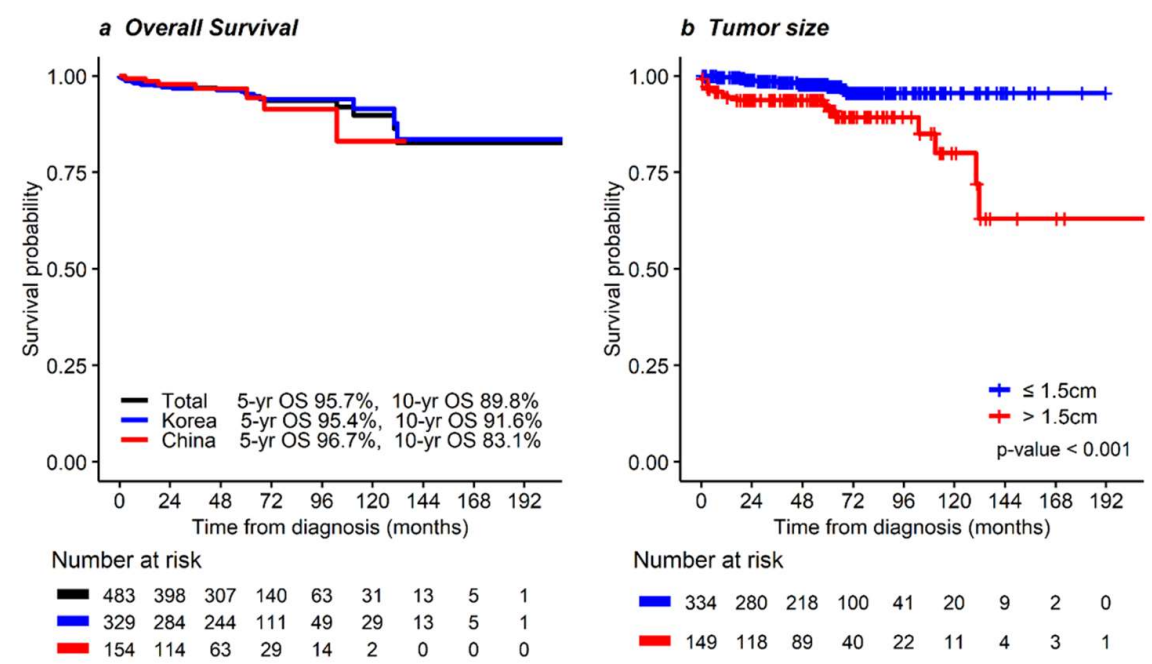

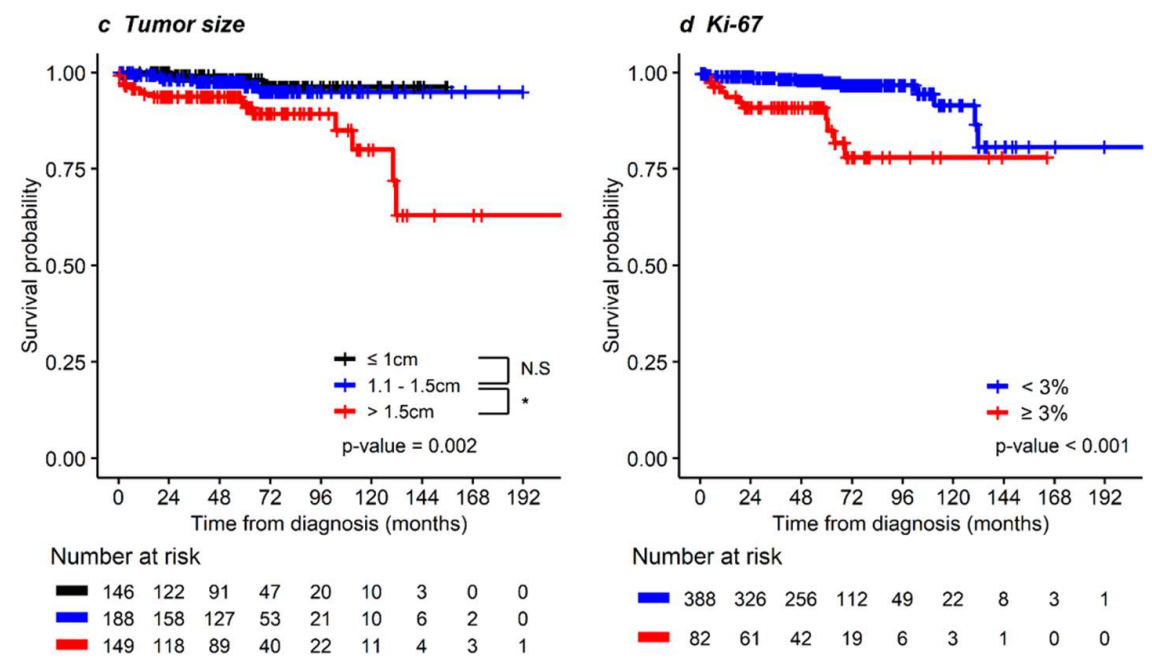

Number at risk
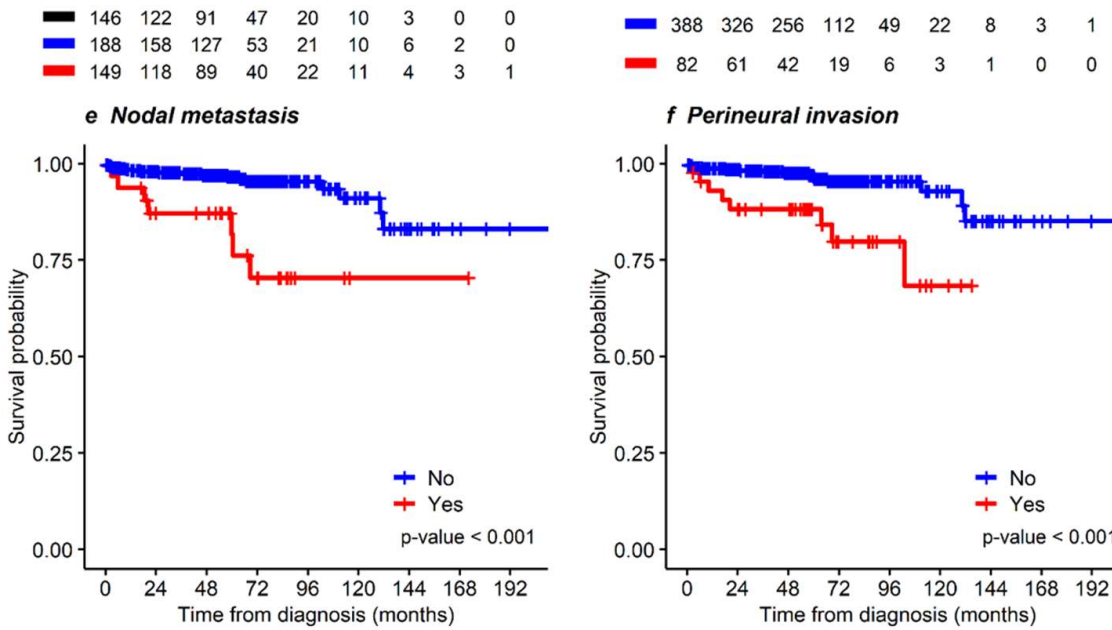

Number at risk

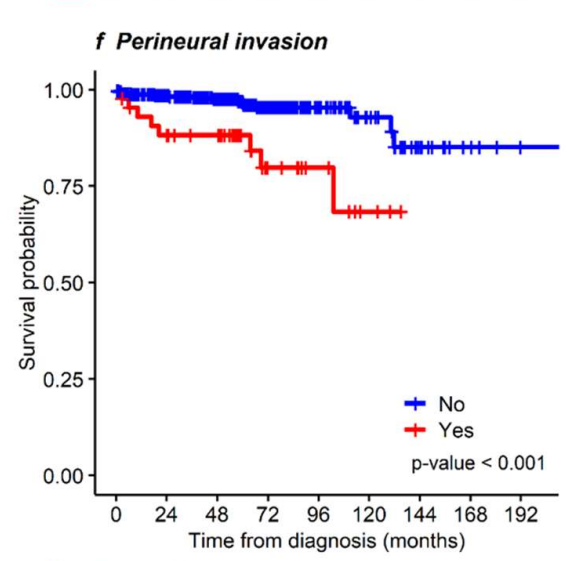

Number at risk

— $\begin{array}{lllllllll}422 & 349 & 270 & 121 & 55 & 29 & 12 & 4 & 1\end{array}$

$\begin{array}{lllllllll}415 & 345 & 270 & 125 & 55 & 28 & 13 & 5 & 1\end{array}$

Fig. 1. Kaplan-Meier curves for overall survival in patients with NF-pNETs $\leq 2 \mathrm{~cm}$

in (a) total, Korean, and Chinese patients and according to (b) tumor size $\leq 1.5$ or $>1.5 \mathrm{~cm}$, (c) tumor size $\leq 1,1$ 1.5 , or $>1.5 \mathrm{~cm}$, (d) Ki-67 index $<3$, or $\geq 3 \%$, (e) nodal metastasis, and (f) perineural invasion 


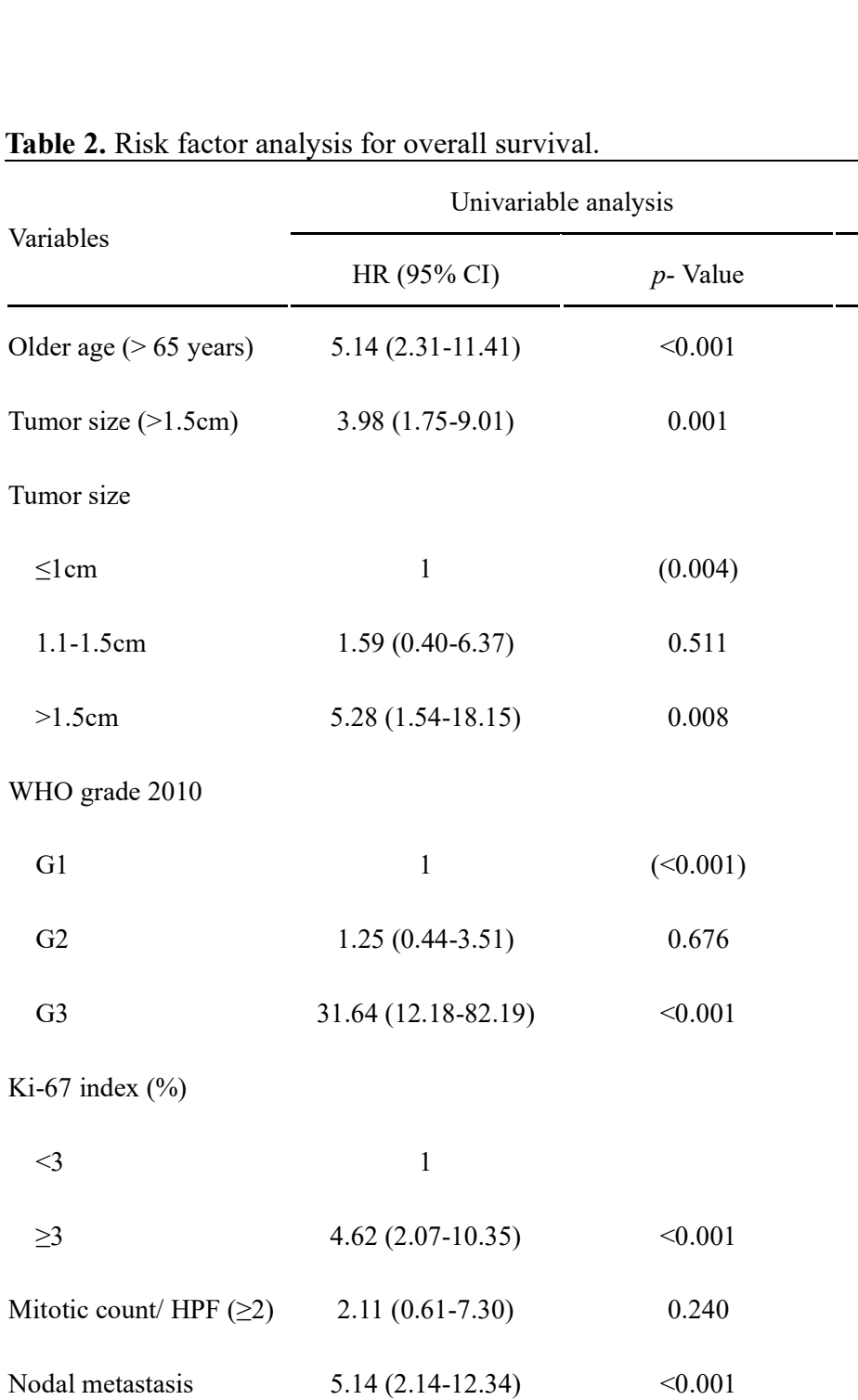

\begin{tabular}{|c|c|c|c|c|}
\hline \multirow{2}{*}{ Variables } & \multicolumn{2}{|c|}{ Univariable analysis } & \multicolumn{2}{|c|}{ Multivariable analysis } \\
\hline & $\mathrm{HR}(95 \% \mathrm{CI})$ & $p$-Value & HR $(95 \%$ CI $)$ & $p$-Value \\
\hline Older age ( $>65$ years) & $5.14(2.31-11.41)$ & $<0.001$ & $4.26(1.84-9.84)$ & 0.001 \\
\hline Tumor size $(>1.5 \mathrm{~cm})$ & $3.98(1.75-9.01)$ & 0.001 & $4.28(1.80-10.18)$ & 0.001 \\
\hline \multicolumn{5}{|l|}{ Tumor size } \\
\hline$\leq 1 \mathrm{~cm}$ & 1 & $(0.004)$ & & \\
\hline $1.1-1.5 \mathrm{~cm}$ & $1.59(0.40-6.37)$ & 0.511 & & \\
\hline$>1.5 \mathrm{~cm}$ & $5.28(1.54-18.15)$ & 0.008 & & \\
\hline
\end{tabular}

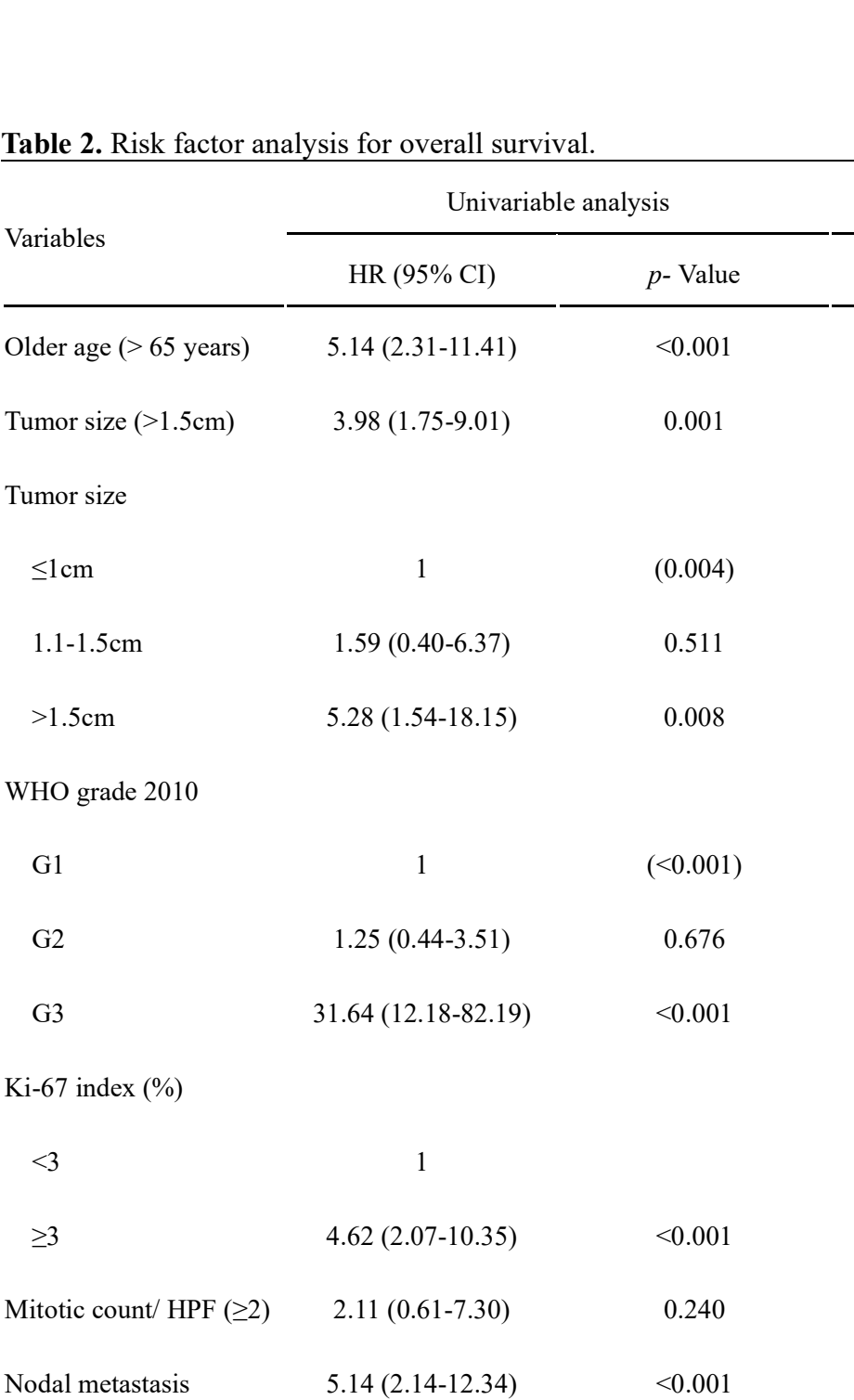

$\begin{array}{ccc}\text { G1 } & 1 & (<0.001) \\ \text { G2 } & 1.25(0.44-3.51) & 0.676 \\ \text { G3 } & 31.64(12.18-82.19) & <0.001\end{array}$

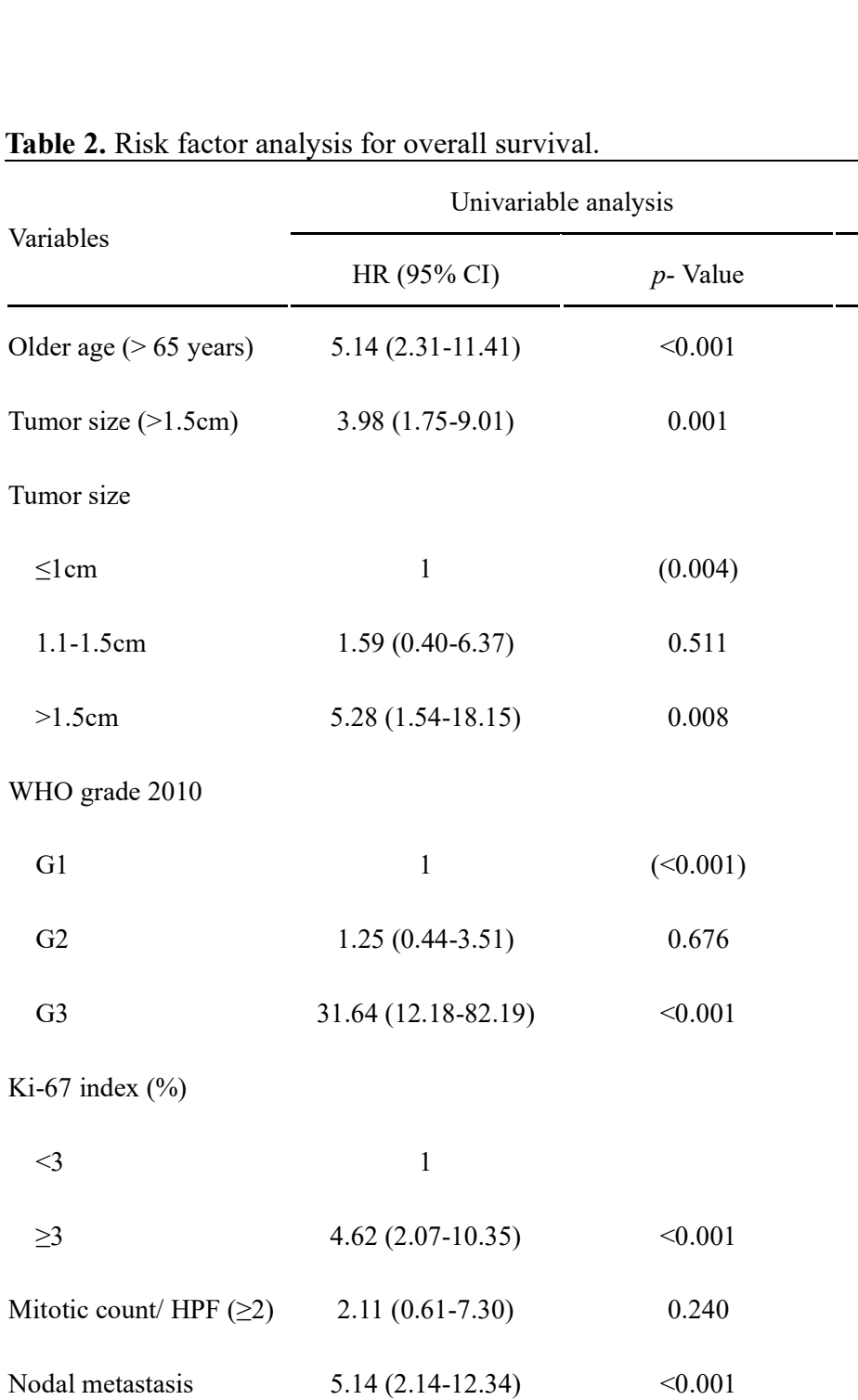

$\begin{array}{ccc}<3 & 1 & \\ \geq 3 & 4.62(2.07-10.35) & <0.001\end{array}$

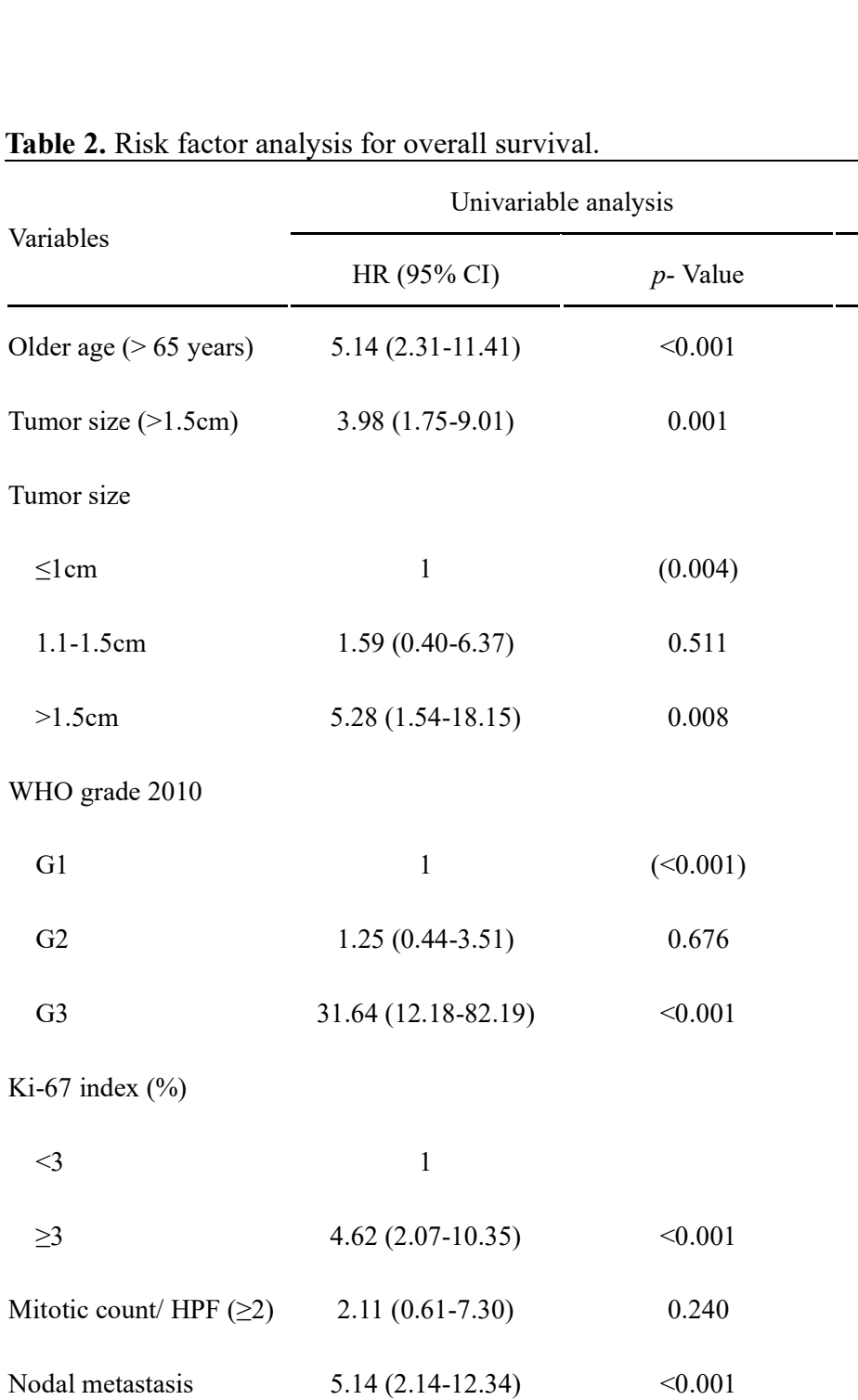

$<0.001 \quad 3.32(1.29-8.50) \quad 0.013$

$\begin{array}{llll}\text { Positive resection margin } & 3.28(1.12-9.62) & 0.031 & 4.30(1.36-13.58)\end{array}$

Vascular invasion $\quad 5.17(2.32-11.56) \quad<0.001$

Perineural invasion $\quad 4.73(2.01-11.11) \quad<0.001$

HR: hazard ratio; CI: confidence interval; HPF: high power field; Multivariable analysis included Ki-67 and mitotic count instead of WHO grade 2010. 

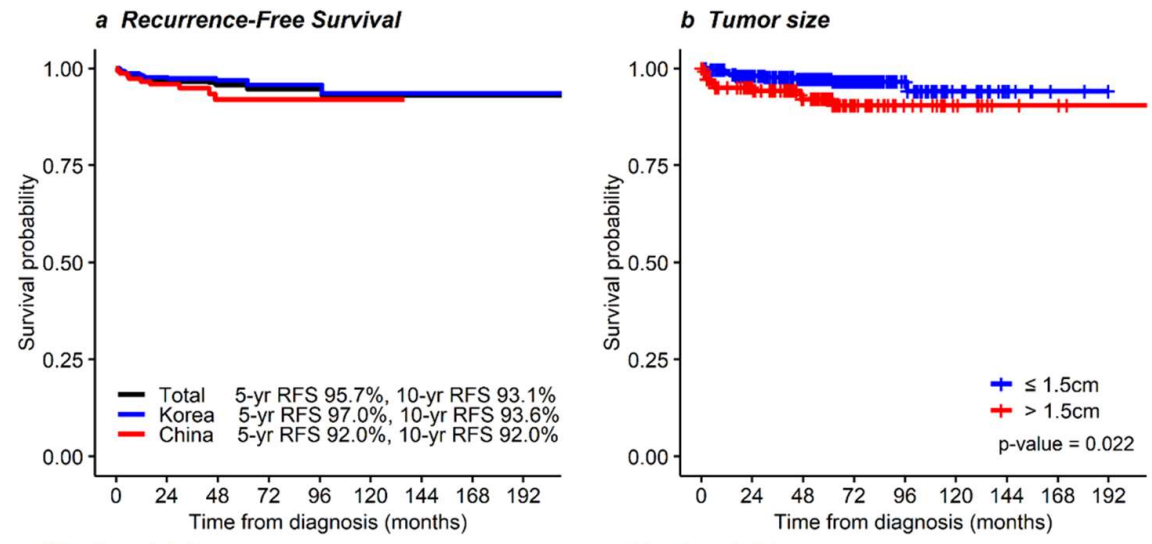
Number at risk

- $\begin{array}{lllllllll}483 & 392 & 298 & 134 & 59 & 29 & 12 & 5 & 1\end{array}$

$\begin{array}{rcccccccc}329 & 281 & 239 & 106 & 46 & 27 & 12 & 5 & 1 \\ 154 & 111 & 59 & 28 & 13 & 2 & 0 & 0 & 0\end{array}$

c $K i-67$

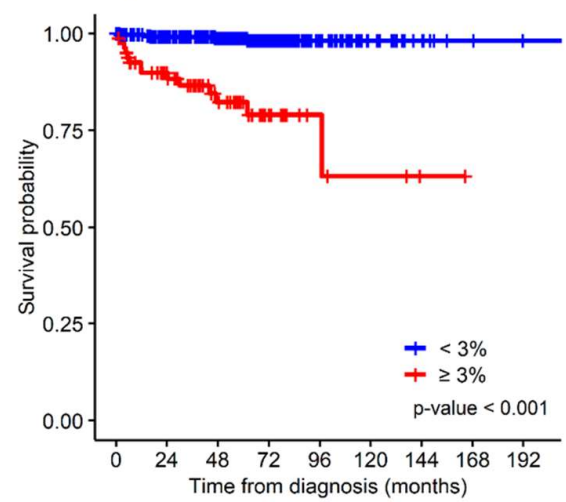
Number at risk

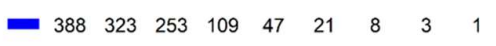

$\begin{array}{lllllllll}82 & 59 & 37 & 17 & 5 & 3 & 1 & 0 & 0\end{array}$

e Vascular invasion

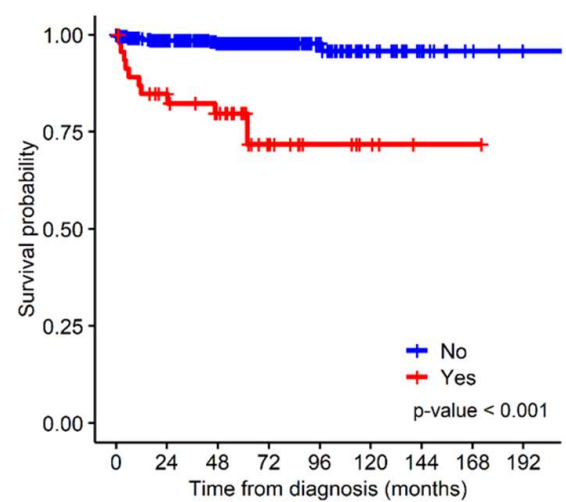

Number at risk

ime from diagnosis (months)

$\begin{array}{lllllllll}416 & 342 & 265 & 119 & 52 & 25 & 11 & 4 & 1\end{array}$

$\begin{array}{lllllllll}334 & 277 & 215 & 97 & 40 & 19 & 8 & 2 & 0\end{array}$

$\begin{array}{rllllllll}-149 & 115 & 83 & 37 & 19 & 10 & 4 & 3 & 1\end{array}$

d Nodal metastasis

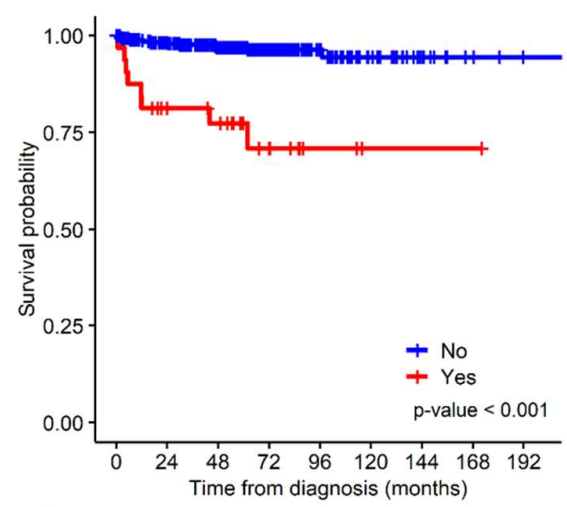

Number at risk

- $\begin{array}{lllllllll}422 & 345 & 264 & 117 & 51 & 27 & 11 & 4 & 1\end{array}$

$\begin{array}{lllllllll}32 & 22 & 20 & 10 & 3 & 1 & 1 & 1 & 0\end{array}$

$f$ Perineural invasion

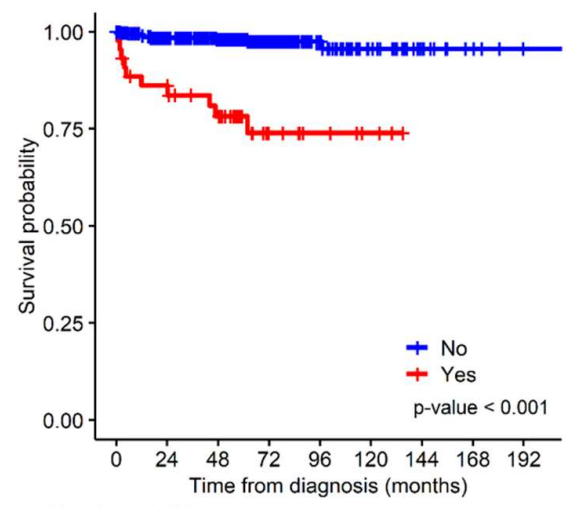

Number at risk

— $\begin{array}{lllllllll}415 & 340 & 265 & 122 & 53 & 26 & 12 & 5 & 1\end{array}$

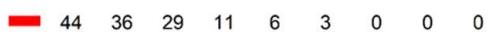

Fig. 2. Kaplan-Meier curves for recurrence-free survival in patients with NF-pNET $\leq 2 \mathrm{~cm}$

in (a) total, Korean, and Chinese patients and according to (b) tumor size $\leq 1.5$ or $>1.5 \mathrm{~cm}$, (c) Ki-67 index $<3$, or $\geq 3 \%$, (d) nodal metastasis, (e) vascular invasion, (f) perineural invasion 
$\underline{\text { Table } 3 \text { Risk factor analysis for recurrence-free survival }}$

\begin{tabular}{|c|c|c|c|c|}
\hline \multirow{2}{*}{ Variables } & \multicolumn{2}{|c|}{ Univariable analysis } & \multicolumn{2}{|c|}{ Multivariable analysis } \\
\hline & $\mathrm{HR}(95 \% \mathrm{CI})$ & $p$-Value & $\mathrm{HR}(95 \% \mathrm{CI})$ & $p$-Value \\
\hline Tumor size $(>1.5 \mathrm{~cm})$ & $2.63(1.12-6.19)$ & 0.027 & & \\
\hline \multicolumn{5}{|l|}{ Tumor size } \\
\hline$\leq 1 \mathrm{~cm}$ & 1 & $(0.072)$ & & \\
\hline $1.1-1.5 \mathrm{~cm}$ & $1.86(0.48-7.20)$ & 0.369 & & \\
\hline$>1.5 \mathrm{~cm}$ & $3.88(1.08-13.92)$ & 0.037 & & \\
\hline \multicolumn{5}{|l|}{ WHO grade 2010} \\
\hline G1 & 1 & $(<0.001)$ & - & - \\
\hline G2 & $6.53(2.19-19.50)$ & 0.001 & - & - \\
\hline G3 & $91.30(28.32-294.32)$ & $<0.001$ & - & - \\
\hline \multicolumn{5}{|l|}{ Ki-67 index (\%) } \\
\hline$<3$ & 1 & & 1 & \\
\hline$\geq 3$ & $15.77(5.66-43.94)$ & $<0.001$ & $9.06(3.01-27.30)$ & $<0.001$ \\
\hline Mitotic count/ HPF $(\geq 2)$ & $2.96(0.81-10.75)$ & 0.100 & & \\
\hline Nodal metastasis & $8.62(3.57-20.80)$ & $<0.001$ & $3.68(1.22-11.11)$ & 0.021 \\
\hline Positive resection margin & $1.96(0.45-8.47)$ & 0.370 & & \\
\hline Adjacent organ invasion & $11.38(3.31-39.12)$ & $<0.001$ & & \\
\hline Vascular invasion & $11.07(4.59-26.74)$ & $<0.001$ & & \\
\hline Perineural invasion & $10.85(4.41-26.71)$ & $<0.001$ & $4.36(1.48-12.87)$ & 0.008 \\
\hline
\end{tabular}

HR: hazard ratio; CI: confidence interval; HPF: high power field; Multivariable analysis included Ki-67 and mitotic count instead of WHO grade 2010.

\section{Discussion}

To the best of our knowledge, this study is the largest multi-institution surgical series from Korea and China (483 patients) to examine sporadic, nonmetastatic NF-pNETs $\leq 2 \mathrm{~cm}$, and thus it provides better external validity than small single-center cohorts.

Although surgery used to be the cornerstone of management for small NF-pNETs, that practice has been recently challenged. In view of the severe and frequent complications following pancreatic surgery and the natural history of sporadic NF-pNET smaller than $2 \mathrm{~cm}$, observation without resection has recently been proposed as a possible option. To date, tumor size has been the main determinant when deciding on an operative or observational policy.[7,10-13,17,19] Recently, several guidelines updates[11,12] recommended initial observation as an acceptable treatment strategy for $\mathrm{pNETs} \leq 2 \mathrm{~cm}$, and more strongly recommended observation 
in cases of $\leq 1 \mathrm{~cm}$. However, no consensus has been reached on whether pNETs between 1 to $2 \mathrm{~cm}$ should be resected or observed.[10] One of the remarkable results of this study is the finding that the size classification criteria should be changed from 1 or $2 \mathrm{~cm}$ to $1.5 \mathrm{~cm}$, as our results indicate that NF-pNETs $\leq 1.5 \mathrm{~cm}$ have a better prognosis than those larger than $1.5 \mathrm{~cm}$ (Table 2). NF-pNETs $\leq 1.5 \mathrm{~cm}$ can be observed because their low risk counterbalances the potential for morbidity, mortality, and exocrine and endocrine deficiencies associated with pancreatic resection. Therefore, changing the surgical indication from $1-2 \mathrm{~cm}$ to $1.5 \mathrm{~cm}$ is reasonable.

Other information to consider when choosing surgical candidates with pNETs smaller than $2 \mathrm{~cm}$ is the rate of nodal metastases. Nodal metastasis predicts poor prognosis.[5,11,14,20-22] In this study, LNM was identified in $32(7.1 \%)$ of 483 patients and was an independent risk factor for poor OS and RFS (Table 2, Table 3). In addition, the rate of nodal metastasis in patients with NF-pNETs smaller than $1.5 \mathrm{~cm}$ was $5.5 \%$ (Table S3). Several previous reports warned that small pNETs, regardless of location, had a risk of LNM from $12.9 \%$ to $27.3 \%$.[11,14,21,22] Although we found that the risk of LNM in patients with small NF-pNETs was lower than in previous studies, we did still find a considerable risk. Thus, standard nodal dissection including suspicious metastatic nodes in preoperative imaging is warranted, and LN sampling can be considered if imaging is negative.

With small NF-pNETs, preoperative endoscopic ultrasound (EUS)-fine needle biopsy (FNB) to determine the $\mathrm{Ki}-67$ level as a predictor of malignancy assists in decision making, because tumor grading has clear implications in terms of prognosis.[23,24] In this study, tumor grading was one of the risk factors for RFS (Table 3). A recent study of data for 210 patients from 16 European centers concluded that patients with grade 2 or 3 tumors, which were independent risk factors for poor disease-free survival, should undergo resection, whereas patients with pNETs smaller than $2 \mathrm{~cm}$, could reasonably be managed with surveillance.[7] Therefore, EUS-FNB should be considered for patients for whom surgical indications are questionable.[11,25]

As in previous studies, $[23,26]$ vascular invasion and perineural invasion were adverse risk factors for survival (Table 2, Table 3). Although it is difficult to determine in preoperative imaging whether vascular or perineural invasions is present, they are clearly factors to be considered before surgery. Age older than 65 years was an adverse prognostic factor for OS (Table 2), so it should play a role in selecting patients for surgery versus surveillance. However, older patients also have a higher risk of mortality from surgery, a higher likelihood of comorbidities, a shorter life expectancy, and shorter surveillance time compared with younger patients. As a result, caution should be taken in interpreting these contradictory results as a uniform endorsement of surgical resection in older patients with small pNETs who will potentially benefit from surgical resection.

Patients with NF- pNETs smaller than $2 \mathrm{~cm}$ have excellent long-term survival, which makes it important to optimize their quality of life in terms of pancreatic function following surgical intervention. A pancreaticoduodenectomy (PD) is the gold standard for lesions of the pancreatic head, whereas a distal pancreatectomy (DP) is used for tumors in the body and tail. However, these surgical procedures are associated with a substantial loss of functional pancreatic and extrapancreatic tissues. In addition, standard pancreatic resections, including multiorgan resection, have considerable postoperative morbidity, a substantial risk of mortality, and inevitable long-term functional impairments, [27,28] and no data support that an aggressive resection to obtain wide surgical margins is justified for pNETs.[11] Parenchyma-sparing resections, including central pancretectomy, enucleation, and duodenal-preserving pancreatic head resection (DPPHR), have been advocated in select pNET patients to minimize morbidity and maintain pancreatic endocrine and exocrine function.[9,27,29] In this study, all variables regarding complications and survival did not show statistically significant differences between PRS and standard resection among the Korean patients (Table S1). As mentioned above, accurate assessment of LNM is important to predict prognosis by staging, and PRS generally has a low lymph node yield rate. In several previous studies, the rate of no lymph node sampling was higher in patients undergoing PRS than in patients who underwent standard operations.[5,11,30,31] Patients with low-risk NF-pNETs $\leq 1.5 \mathrm{~cm}$, who are predicted to have long survival times, and those who develop pNETs at a young age have the most to gain from preserved pancreatic function and can thus be considered most appropriate for planned PRS with selective lymphadenectomy instead of a standard resection. Whether to proceed with PRS or a standard resection is a delicate decision, that should be discussed and preferably made with the patients.

As in this study (Table S2), other studies have reported favorable results from Minimally- invasive surgery (MIS) compared with conventional open pancreatectomy.[32-36] Several guidelines have considered different approaches for resecting pNETs, especially those in the tail of the pancreas, and laparoscopic or robotic DP has been considered to be safe and effective with satisfactory postoperative and oncologic outcomes. $[8,11,35,37]$ Unlike with DP, results with MIS PD might not be as favorable as those from the conventional open approach.[38,39] Therefore, left-sided pancreatectomy should consider a laparoscopic or robotic approach first, but minimally-invasive PD should be approached carefully considering the surgeon's experience or the condition of the patient. 
The present study has several limitations. First, we only had access to data on patients who underwent resection, and how many patients were under surveillance in the participating centers during the same period is unknown. If long-term RFS after curative surgery is excellent, the results of non-operative management are of prime interest. Second, this study did not have data about the size discrepancy between preoperative CT images and pathologic reports. Sallinen et al.[7] reported that significant discrepancies those measurements should be noted. In addition, we could obtain information about the type of surgery or surgical complications only from the Korea multicenter database. If that information could have been included in the multivariable analysis process, more sophisticated and reliable statistical analysis would have been possible. Last, selection bias could have affected the retrospective analysis.

\section{Methods}

\subsection{Patients and data collection}

Patients with symptoms and biochemical evidence of excess pancreatic hormone are considered to have functioning pNETs, whereas patients with no symptoms, normal serum hormone levels, and no hereditary syndrome such as MEN type I are considered to have sporadic NF-pNETs.[11] Under Institutional Review Board approval (number: 2019-03-160-001), we retrospectively analyzed the clinicopathological variables of 329 Korean patients from 10 institutes participating in the Korean Tumor Registry System-Biliary Pancreas (KOTUSBP) and 154 Chinese patients from 8 institutes. All institutions participating in this study are tertiary referral highvolume centers, and all patients were treated based on the guideline or consensus at the time. All participants underwent resection to treat sporadic, nonmetastatic NF-pNETs smaller than $2 \mathrm{~cm}$ between November 2000 and December 2017. When necessary, additional retrospective medical record review was performed.

Variables collected for this work were age at diagnosis, sex, tumor size, location, nodal metastasis, perineural invasion, WHO 2010 tumor grade, mitotic count, Ki-67 index, and duration of follow-up. The OS time was defined as the time from the date of operation to the date of death or last known follow-up. The RFS time was measured from the date of operation until recurrence. Follow-up was updated in March 2020. In addition, information on surgery and complications was obtained for Korean patients. For these patients, postoperative complications were classified using the Clavien-Dindo classification. PSRs included central pancreatectomy, enucleation, and DPPHR, and standard resections involved PD or DP. MIS included laparoscopic or robotic resection of the pancreas. Major complications were defined as Clavien-Dindo grade III or higher. POPF was defined using the 2016 International Study Group on Pancreatic Fistula definition.[18]

\subsection{Statistical analysis}

The baseline characteristics were summarized as median value (range) or frequency (percentage). Comparisons of variables and postoperative complications were performed using Chi-squared test. OS and RFS rates were estimated using Kaplan-Meier method, and the survival curves were presented with $p$ of $\log$-rank tests. The clinicopathological features associated with OS and RFS were analyzed using Cox proportional hazards models. Statistically significant variables in univariable analysis were included in multivariable analysis. The final model was determined using the backward selection method with elimination criterion of $p>0.05$. Hazard ratios (HRs) and their $95 \%$ confidence intervals (CIs) were presented, and $P$ less than 0.05 indicated statistical significance. All statistical analyses were performed using SAS version 9.4 (SAS Institute, Cary, NC, USA) and R project software (version 3.6.2).

\section{Conclusions}

NF-pNETs smaller than $2 \mathrm{~cm}$ showed considerable recurrence after resection when the tumor was larger than $1.5 \mathrm{~cm}, \mathrm{Ki}-67$ index was over $3 \%$, or nodal metastasis was present. NF-pNET patients with tumors $\leq 1.5 \mathrm{~cm}$ can be observed without resection if the preoperative $\mathrm{Ki}-67$ index is low, assuming preoperative tissue diagnosis is possible, and nodal metastasis is not suspected in preoperative radiologic studies. Therefore, the proposed surgical indication is expected to help stratify the patient's prognosis and provide comprehensive clinical decision- making.

Author Contributions: Conceptualization, I.W.H., W.L., and S.-J.P.; formal analysis, I.W.H., S.J.Y., J.P., E.Y.P, and S.-J.P.; funding acquisition, I.W.H., and S.-J.P.; investigation, I.W.H., S.J.Y., J.P., E.Y.P., G.J., D.W.H., K.J., W.K., X.X., J.S.H., D.F., W.J.L., X.B., Y.-S.Y., Y.Y., K.S.A., C.Y., H.K.L., B.S., E.K.P., S.E.L., S.K., W.L., and S.-J.P.; methodology, I.W.H, W.L., and S.-J.P.; project administration, I.W.H, W.L., and S.-J.P.; resources, I.W.H., S.J.Y., J.P., E.Y.P., G.J., D.W.H., K.J., W.K., X.X., J.S.H., D.F., W.J.L., X.B., Y.-S.Y., Y.Y., K.S.A., C.Y., 
H.K.L., B.S., E.K.P., S.E.L., S.K., W.L., and S.-J.P.; software, I.W.H., E.Y.P., and S.-J.P; supervision, W.L., and S.-J.P.; visualization, I.W.H., S.J.Y., J.P., and E.Y.P.; writing—original draft, I.W.H., S.J.Y., E.Y.P.; writingreview and editing, I.W.H., S.J.Y., J.P., E.Y.P., G.J., D.W.H., K.J., W.K., X.X., J.S.H., D.F., W.J.L., X.B., Y.-S.Y., Y.Y., K.S.A., C.Y., H.K.L., B.S., E.K.P., S.E.L., S.K., W.L., and S.-J.P.

Funding: This study was supported by the Research Program of the Korean Association for Hepato-BiliaryPancreatic Surgery for 2019 (KAHPBS-2019-33).

Acknowledgements: We thank the study research nurses Hyemin Kim at Samsung Medical Center and Gang-Hun Lee at Dongguk University Ilsan Hospital for their work in data acquisition.

Conflicts of Interest: The authors declare no conflicts of interest.

\section{References}

1. Modlin, I.M.; Moss, S.F.; Chung, D.C.; Jensen, R.T.; Snyderwine, E. Priorities for improving the management of gastroenteropancreatic neuroendocrine tumors. J Natl Cancer Inst 2008, 100, 1282-1289.

2. Kuo, J.H.; Lee, J.A.; Chabot, J.A. Nonfunctional pancreatic neuroendocrine tumors. Surg Clin North Am 2014, 94, 689-708.

3. Panzuto, F.; Boninsegna, L.; Fazio, N.; Campana, D.; Pia Brizzi, M.; Capurso, G.; Scarpa, A.; De Braud, F.; Dogliotti, L.; Tomassetti, P.; et al. Metastatic and locally advanced pancreatic endocrine carcinomas: analysis of factors associated with disease progression. J Clin Oncol 2011, 29, 2372-2377.

4. Metz, D.C.; Jensen, R.T. Gastrointestinal neuroendocrine tumors: pancreatic endocrine tumors. Gastroenterology 2008, 135, 1469-1492.

5. You, Y.; Jang, J.Y.; Kim, S.C.; Yoon, Y.S.; Park, J.S.; Cho, C.K.; Park, S.J.; Yang, J.D.; Lee, W.J.; Hong, T.H.; et al. Validation of the 8th AJCC Cancer Staging System for Pancreas Neuroendocrine Tumors Using Korean Nationwide Surgery Database. Cancer Res Treat 2019, 51, 1639-1652.

6. Yao, J.C.; Hassan, M.; Phan, A.; Dagohoy, C.; Leary, C.; Mares, J.E.; Abdalla, E.K.; Fleming, J.B.; Vauthey, J.N.; Rashid, A.; et al. One hundred years after "carcinoid": epidemiology of and prognostic factors for neuroendocrine tumors in 35,825 cases in the United States. J Clin Oncol 2008, 26, 30633072 .

7. Sallinen, V.J.; Le Large, T.Y.S.; Tieftrunk, E.; Galeev, S.; Kovalenko, Z.; Haugvik, S.P.; Antila, A.; Franklin, O.; Martinez-Moneo, E.; Robinson, S.M.; et al. Prognosis of sporadic resected small $(\leq 2 \mathrm{~cm})$ nonfunctional pancreatic neuroendocrine tumors - a multi-institutional study. HPB (Oxford) 2018, 20, 251-259.

8. Falconi, M.; Eriksson, B.; Kaltsas, G.; Bartsch, D.K.; Capdevila, J.; Caplin, M.; Kos-Kudla, B.; Kwekkeboom, D.; Rindi, G.; Klöppel, G.; et al. ENETS Consensus Guidelines Update for the Management of Patients with Functional Pancreatic Neuroendocrine Tumors and Non-Functional Pancreatic Neuroendocrine Tumors. Neuroendocrinology 2016, 103, 153-171.

9. Singh, S.; Dey, C.; Kennecke, H.; Kocha, W.; Maroun, J.; Metrakos, P.; Mukhtar, T.; Pasieka, J.; Rayson, D.; Rowsell, C.; et al. Consensus Recommendations for the Diagnosis and Management of Pancreatic Neuroendocrine Tumors: Guidelines from a Canadian National Expert Group. Ann Surg Oncol 2015, 22, 2685-2699.

10. Mansour, J.C.; Chavin, K.; Morris-Stiff, G.; Warner, S.G.; Cardona, K.; Fong, Z.V.; Maker, A.; Libutti, S.K.; Warren, R.; St Hill, C.; et al. Management of asymptomatic, well-differentiated PNETs: results of the Delphi consensus process of the Americas Hepato-Pancreato-Biliary Association. HPB (Oxford) 2019, 21, 515-523.

11. Howe, J.R.; Merchant, N.B.; Conrad, C.; Keutgen, X.M.; Hallet, J.; Drebin, J.A.; Minter, R.M.; Lairmore, T.C.; Tseng, J.F.; Zeh, H.J.; et al. The North American Neuroendocrine Tumor Society Consensus Paper on the Surgical Management of Pancreatic Neuroendocrine Tumors. Pancreas 2020, 49 , $1-33$.

12. https://www.nccn.org/professionals/physician_gls/default.aspx\# neuroendocrine.

13. Sadot, E.; Reidy-Lagunes, D.L.; Tang, L.H.; Do, R.K.; Gonen, M.; D'Angelica, M.I.; DeMatteo, R.P.; Kingham, T.P.; Groot Koerkamp, B.; Untch, B.R.; et al. Observation versus Resection for Small Asymptomatic Pancreatic Neuroendocrine Tumors: A Matched Case-Control Study. Ann Surg Oncol 
2016, 23, 1361-1370.

14. Toste, P.A.; Kadera, B.E.; Tatishchev, S.F.; Dawson, D.W.; Clerkin, B.M.; Muthusamy, R.; Watson, R.; Tomlinson, J.S.; Hines, O.J.; Reber, H.A.; et al. Nonfunctional pancreatic neuroendocrine tumors $<2 \mathrm{~cm}$ on preoperative imaging are associated with a low incidence of nodal metastasis and an excellent overall survival. J Gastrointest Surg 2013, 17, 2105-2113.

15. Haynes, A.B.; Deshpande, V.; Ingkakul, T.; Vagefi, P.A.; Szymonifka, J.; Thayer, S.P.; Ferrone, C.R.; Wargo, J.A.; Warshaw, A.L.; Fernández-del Castillo, C. Implications of incidentally discovered, nonfunctioning pancreatic endocrine tumors: short-term and long-term patient outcomes. Arch Surg 2011, 146, 534-538.

16. Sharpe, S.M.; In, H.; Winchester, D.J.; Talamonti, M.S.; Baker, M.S. Surgical resection provides an overall survival benefit for patients with small pancreatic neuroendocrine tumors. J Gastrointest Surg 2015, 19, 117-123; discussion 123.

17. Finkelstein, P.; Sharma, R.; Picado, O.; Gadde, R.; Stuart, H.; Ripat, C.; Livingstone, A.S.; Sleeman, D.; Merchant, N.; Yakoub, D. Pancreatic Neuroendocrine Tumors (panNETs): Analysis of Overall Survival of Nonsurgical Management Versus Surgical Resection. J Gastrointest Surg 2017, 21, 855-866.

18. Bassi, C.; Marchegiani, G.; Dervenis, C.; Sarr, M.; Abu Hilal, M.; Adham, M.; Allen, P.; Andersson, R.; Asbun, H.J.; Besselink, M.G.; et al. The 2016 update of the International Study Group (ISGPS) definition and grading of postoperative pancreatic fistula: 11 Years After. Surgery 2017, 161, 584-591.

19. Bettini, R.; Boninsegna, L.; Mantovani, W.; Capelli, P.; Bassi, C.; Pederzoli, P.; Delle Fave, G.F.; Panzuto, F.; Scarpa, A.; Falconi, M. Prognostic factors at diagnosis and value of WHO classification in a mono-institutional series of 180 non-functioning pancreatic endocrine tumours. Ann Oncol 2008, 19, 903-908.

20. Hashim, Y.M.; Trinkaus, K.M.; Linehan, D.C.; Strasberg, S.S.; Fields, R.C.; Cao, D.; Hawkins, W.G. Regional lymphadenectomy is indicated in the surgical treatment of pancreatic neuroendocrine tumors (PNETs). Ann Surg 2014, 259, 197-203.

21. Kuo, E.J.; Salem, R.R. Population-level analysis of pancreatic neuroendocrine tumors $2 \mathrm{~cm}$ or less in size. Ann Surg Oncol 2013, 20, 2815-2821.

22. Sallinen, V.; Haglund, C.; Seppänen, H. Outcomes of resected nonfunctional pancreatic neuroendocrine tumors: Do size and symptoms matter? Surgery 2015, 158, 1556-1563.

23. Landoni, L.; Marchegiani, G.; Pollini, T.; Cingarlini, S.; D'Onofrio, M.; Capelli, P.; De Robertis, R.; Davì, M.V.; Amodio, A.; Impellizzeri, H.; et al. The Evolution of Surgical Strategies for Pancreatic Neuroendocrine Tumors (Pan-NENs): Time-trend and Outcome Analysis From 587 Consecutive Resections at a High-volume Institution. Ann Surg 2019, 269, 725-732.

24. Scarpa, A.; Mantovani, W.; Capelli, P.; Beghelli, S.; Boninsegna, L.; Bettini, R.; Panzuto, F.; Pederzoli, P.; delle Fave, G.; Falconi, M. Pancreatic endocrine tumors: improved TNM staging and histopathological grading permit a clinically efficient prognostic stratification of patients. Mod Pathol 2010, 23, 824-833.

25. Phan, J.; Dawson, D.; Sedarat, A.; Fejleh, M.P.; Marya, N.; Thaker, A.M.; Rogers, M.; Kim, S.; Muthusamy, V.R. Clinical Utility of Obtaining Endoscopic Ultrasound-Guided Fine-Needle Biopsies for Histologic Analyses of Pancreatic Cystic Lesions. Gastroenterology 2020, 158, 475-477.e471.

26. Genç, C.G.; Jilesen, A.P.; Partelli, S.; Falconi, M.; Muffatti, F.; van Kemenade, F.J.; van Eeden, S.; Verheij, J.; van Dieren, S.; van Eijck, C.H.J.; et al. A New Scoring System to Predict Recurrent Disease in Grade 1 and 2 Nonfunctional Pancreatic Neuroendocrine Tumors. Ann Surg 2018, 267, 1148-1154.

27. Beger, H.G.; Mayer, B.; Rau, B.M. Parenchyma-Sparing, Limited Pancreatic Head Resection for Benign Tumors and Low-Risk Periampullary Cancer--a Systematic Review. J Gastrointest Surg 2016, 20, 206217.

28. Ghaferi, A.A.; Birkmeyer, J.D.; Dimick, J.B. Variation in hospital mortality associated with inpatient surgery. N Engl J Med 2009, 361, 1368-1375.

29. Hüttner, F.J.; Koessler-Ebs, J.; Hackert, T.; Ulrich, A.; Büchler, M.W.; Diener, M.K. Meta-analysis of surgical outcome after enucleation versus standard resection for pancreatic neoplasms. Br J Surg 2015, 102, 1026-1036.

30. Parekh, J.R.; Wang, S.C.; Bergsland, E.K.; Venook, A.P.; Warren, R.S.; Kim, G.E.; Nakakura, E.K. Lymph node sampling rates and predictors of nodal metastasis in pancreatic neuroendocrine tumor resections: the UCSF experience with 149 patients. Pancreas 2012, 41, 840-844.

31. Rindi, G.; Falconi, M.; Klersy, C.; Albarello, L.; Boninsegna, L.; Buchler, M.W.; Capella, C.; Caplin, M.; Couvelard, A.; Doglioni, C.; et al. TNM staging of neoplasms of the endocrine pancreas: results from a large international cohort study. J Natl Cancer Inst 2012, 104, 764-777. 
32. Drymousis, P.; Raptis, D.A.; Spalding, D.; Fernandez-Cruz, L.; Menon, D.; Breitenstein, S.; Davidson, B.; Frilling, A. Laparoscopic versus open pancreas resection for pancreatic neuroendocrine tumours: a systematic review and meta-analysis. HPB (Oxford) 2014, 16, 397-406.

33. Xourafas, D.; Tavakkoli, A.; Clancy, T.E.; Ashley, S.W. Distal pancreatic resection for neuroendocrine tumors: is laparoscopic really better than open? J Gastrointest Surg 2015, 19, 831-840.

34. Han, S.H.; Han, I.W.; Heo, J.S.; Choi, S.H.; Choi, D.W.; Han, S.; You, Y.H. Laparoscopic versus open distal pancreatectomy for nonfunctioning pancreatic neuroendocrine tumors: a large single-center study. Surg Endosc 2018, 32, 443-449.

35. de Rooij, T.; van Hilst, J.; van Santvoort, H.; Boerma, D.; van den Boezem, P.; Daams, F.; van Dam, R.; Dejong, C.; van Duyn, E.; Dijkgraaf, M.; et al. Minimally Invasive Versus Open Distal Pancreatectomy (LEOPARD): A Multicenter Patient-blinded Randomized Controlled Trial. Ann Surg 2019, 269, 2-9.

36. Zureikat, A.H.; Postlewait, L.M.; Liu, Y.; Gillespie, T.W.; Weber, S.M.; Abbott, D.E.; Ahmad, S.A.; Maithel, S.K.; Hogg, M.E.; Zenati, M.; et al. A Multi-institutional Comparison of Perioperative Outcomes of Robotic and Open Pancreaticoduodenectomy. Ann Surg 2016, 264, 640-649.

37. de Rooij, T.; Klompmaker, S.; Abu Hilal, M.; Kendrick, M.L.; Busch, O.R.; Besselink, M.G. Laparoscopic pancreatic surgery for benign and malignant disease. Nat Rev Gastroenterol Hepatol 2016, 13, 227-238.

38. van Hilst, J.; de Rooij, T.; Bosscha, K.; Brinkman, D.J.; van Dieren, S.; Dijkgraaf, M.G.; Gerhards, M.F.; de Hingh, I.H.; Karsten, T.M.; Lips, D.J.; et al. Laparoscopic versus open pancreatoduodenectomy for pancreatic or periampullary tumours (LEOPARD-2): a multicentre, patient-blinded, randomised controlled phase 2/3 trial. Lancet Gastroenterol Hepatol 2019, 4, 199-207.

39. Ricci, C.; Casadei, R.; Taffurelli, G.; Pacilio, C.A.; Ricciardiello, M.; Minni, F. Minimally Invasive Pancreaticoduodenectomy: What is the Best "Choice"? A Systematic Review and Network Meta-analysis of Non-randomized Comparative Studies. World J Surg 2018, 42, 788-805. 